\title{
Economic Model Analysis of Enterprise Brand after Introducing Personal Brand
}

\author{
Nan Sha (Corresponding author) \\ School of Economics, Shandong University \\ 27 Shanda Nanlu, Jinan 250100, Shandong, China \\ Tel: 86-531-5897-4341Ｅ-mail: sevensha@gmail.com \\ Min Wang \\ School of Economics, Shandong University \\ 27 Shanda Nanlu, Jinan 250100, Shandong, China \\ Tel: 86-531-8836-9510 E-mail: 61802214@qq.com \\ Wenhua Yuan \\ School of Economics, Shandong University \\ 27 Shanda Nanlu, Jinan 250100, Shandong, China \\ Tel: 86-531-8836-9510 E-mail: 492378340@qq.com
}

\begin{abstract}
Regarding the hospital as a special enterprise whose output is information, this article shows that the demand curve of the hospital rotates in a clockwise direction. That means the elasticity of the curve becomes lesser, which is useful for the hospital to implement the second-degree price discrimination. The reason is that the distribution of the unit price that the consumer willing to pay becomes more dispersed when the information outcome contains personal brand and enterprise brand. The combination of the personal brand (specialist brand, etc.) and product brand (drugs made-by-the-hospital, etc.) is the base of the hospital's brand. This article analyzes the relationship among the three brands under a unified framework from the aspect of the product popularity. This article shows that the high product popularity cannot change into the actual sales revenue until the hospital obtains high product popularity by reflecting the consumer's single profit point. Therefore, this article suggested the enterprise to focus on the single category of their products to get the consumers' vote (i.e. currency).
\end{abstract}

Keywords: The accurate of the information, Personal brand, Hospital brand, Brand credit degree

\section{Introduction}

Public hospital in China is a kind of special enterprises owned by the government. They receive government funding and enjoy preferential tax policies, and the government stipulates the price of their medical service. The government provides compensation to the hospitals' infrastructure construction, large scale hospital equipment, key disciplines, and research funding. The public hospital should complete the tasks given by the government, such as the amount of the basic medical service. Public hospital is the major medical institution of the country, including infectious disease hospital, Preventive hospital, medium-sized general hospital and university hospital which guide the development of the medical direction.

\subsection{The Medical Environment in China}

The data from the Ministry of health shows that, as of the end of November 2009, there are more than 1.4 thousand public hospitals in China. The distribution of the general public hospitals is as follows: 4026 in the east, 3617 in the middle part and 3213 in the west. Nearly $90 \%$ patients choose the public hospitals in the total number of 1.9 billion patients (2009 China Health Statistics Yearbook). Hospital is a special kind of enterprises not only because its product structure is particular, but also the product (information) is necessity for the consumers whoever needed. In fact, the information outcome accounts for a large proportion in the per capital consumption. We take three provinces separately from the east, middle and west part as an example to see the proportion. The result shows that the proportion of information consumption in the east part of China is smaller 
than it in the middle and west parts. The proportion for the outpatients is smaller than the inpatients in all areas. The distribution in the time axis is the same.

What's more, the information containing personal brand is scarce, because the amount of the specialists and the public hospitals are limited. From 1978 to 2005, the demand for medical services from government, institutions and individuals increases by about 78 -fold, in which the demand of individuals increased by 200 -fold. On the other hand, the supply of the medical institutions increased by only $76 \%$ during this period of time, in which the number of hospitals has doubled and cliniques rise less than tripled. The demand and supply are serious imbalance. The statistics in 2005 showed that $4 \%$ were professors and $17.9 \%$ were associate professors in the practicing physicians (2009 China Health Statistics Yearbook).

Table 1

The proportion of information products in the per capital consumption in the public hospital in 2008

The proportion of information consumption for the outpatients is smaller than the inpatients in the time axis. It is shown in table 2.

\section{Table 2}

The proportion of information consumption for the outpatients and the inpatients in the time axis

\subsection{The Basic Hypothesizes and Definitions}

Hospital belongs to the information industry. The patient should "input" some information to the doctor (such as why he not feel well), then the doctor analyzes the information according to his experience and knowledge, and finally, the doctor "output" the information - diagnosis - back to the patient. Suppose hospital is a firm with products (drugs) and labor (doctors), the questions are how to put the hospital brand (enterprise brand), product brand (drug brand), and personal brand (specialist brand) into a framework to analyze, and what the interrelationship among them is. Life is full of uncertainty, but the brand including product brand and personal brand could reduce very uncertainty. Information asymmetries exist between producers and consumers, so the consumers' choice cost is much high when they face with a large number of information. In this case, brand can reduce the consumers' choice cost by giving them a reason to choose without thinking. Thus for the hospitals, the information contained in its brand can reduce the consumers' choice cost sharply.

Definition 1: Choice cost. After the transaction cost (e.g. search cost), consumers can get a set of brands; Choice cost is the cost consumers spend on the final choice through comparing these brands.

Definition 2: Brand Credit Degree. Brand credit degree means how much degree the enterprise has done to the category which it had promised to the target customer by exclusive symbol.

\subsection{Literature Review}

Hospital is one of typical service industry, which provides material product (e.g. medicine) and information product (e.g. diagnosis and symptoms analysis). All products and services provide the target consumers both the material and information product, but each of them focuses on different aspects. The traditional brand theories emphasize the brand construction of products (Aaker, 1996; Kapferer, 1997; Keller, 1993). However, the brand construction of services is more important and difficult for its fast growth and intangible. O'cass and Grace (2003) advance the service brand contains the name, price, service environment, core service, staff service, and the coherence of the emotion and image. The service brand has more points of contact for the consumer than the product brand, which means consumer can know the brand form more aspects. Meanwhile, consumers cannot evaluate the service until they buy it as it is intangible. If the consumption experience is not as good as the brand has promised to the consumers, they will dissatisfied (De Chernatony, 2003). If the patients are not satisfied for the first time in one hospital, they will not choose it again. Therefore, the hospital should focus on the improvement of the patients' experiment during the whole process. Brand identity has four perspectives: brand for the product (product brand), brand for the organization (enterprise brand), brand for a person (brand personality), and brand for the symbol (brand symbolism) (Aaker, 1996). As the product is much special, the brand construction of hospital contains hospital brand construction, product brand construction and personal brand construction. The hospital brand construction is the traditional enterprise brand construction (Creye and Ross, 1996; Goldberg and Hartwick, 1990; Dacin and Brown, 2002; Aaker, 1997), and the personal brand construction can be realized by hiring doctors and specialists with high popularity.

This article is organized as follows: firstly, solve the question why the demand curve's elasticity of hospital with brand is lower than the ones without it? That is why consumers' demand for the well-known hospital more than the ordinary hospital. The other question is why firms established brand have stronger pricing power? Then we 
put the hospital brand, product brand, and personal brand into a framework, and then we get functions about them after analyzing. Finally, we have the result.

\section{The rotation of the demand curve after the personal brand is introduced in the enterprise brand}

Suppose that the patients' maximum willingness to pay for unit information is $\theta$ when they goes to the hospital to "buy" information, the total amount of the consumers is a unit, and the cumulative distribution function (CDF) of $\theta$ on an interval $\left(\theta_{s}, \bar{\theta}_{s}\right)$ is $F_{s}(\theta)$ which is Second-order continuously differentiable to $\theta$ and $s$. $f_{s}(\theta)$ indicates a strictly positive density function, in which parameter $s \in S=\left[s_{L}, s_{H}\right]$ is a group of distribution function with different dispersion parameter. $s_{N B} \in S$ is the distribution parameter of $\theta$ while the patients do not know whether the unit information is "output" by a specialist or a ordinary doctor; $S_{B} \in S$ is the distribution parameter of $\theta$ while the patients know the unit information is given by a specialist; and obviously $s_{B}>s_{N B}$. If patients do not know the source of the information, their maximum willingness to pay for unit information $\theta$ is more concentrated. If patients know the information is given by specialists, the distribution of $\theta$ is more dispersed. For example, patients are willing to pay more to the doctors who have studied aboard or who often deal with such disease (that is the reason why the fee for registration in the well-known hospital is higher). On the other hand, when patients do not care the background of the specialists, the price they are willing to give may not change seriously. However, if patients know some specialists have failed to deal with such disease before, they would pay less for unit information.

\subsection{The demand equation of information}

The information that doctors give to the patients includes what illness the patient have, what medicine he should take, what he should to his dietary habits, what the frequency and side effects of the drug are, as well as how long he should go back to have reexamination. Suppose information is quantifiable, and unit information is one unit of the total information that the doctors give to the patients. Assume the average price per unit information is $p$ and the doctors give $N$ piece of information in all. Each piece contains the amount of information $n_{i}$.

Here $n_{i}$ only contains the valuable information for patients, excluding the information patients already known.

For example, the patient already known what illness he has and what medicine he should take through internet, and then he goes to the hospital only for the Prescription drugs. In this case, patients get no valuable information from doctors, so $n_{i}$ is zero. The patients' main cost includes the fee for registration $G$ and other fees $T$ \[ p=\frac{G+T}{\sum_{i=1}^{N} n_{i}} \text {. The purpose to suppose } n_{i} \]
which involves fees for examination, etc. Then we get the function
does not contain what the patients already known is to get $p \rightarrow \infty$ when $\sum_{i=1}^{N} n_{i} \rightarrow 0$. Rational consumers will not buy the repeat "output" of the doctors, so it avoid the case that patients go to the same doctor to buy the useless information when $\theta \geq p$.

Given a fixed unit price $p$, the number of patients who will buy the information is $z=1-F_{s}(p)$. As suppose the total number of patients is one unit, the total amount of information sold is $z$. Please note that patients may not buy all information given by the doctors for one time. They may refuse some of it, such as some expensive examination. Examination is the first step of treatment, which is obviously important. The medical examinations are various and play different roles. 


\subsubsection{Supplier-induce demand}

The examinations commonly used may not the most appropriate but the most expensive ones. In fact, a lot of examinations are not necessary. However, consumers cannot make rational judgment because of information asymmetry between patients and physicians (Laffont and Tirole, 1993). Thus the supplier-induce demand (SID, Peter Zweifel 2009. Health economics.p.296) from doctors may cause the consumers' excessive buying. Suppose the consumers are rational in order to facilitate the analysis. Thus the reason for excessive examination is that patients depend more on the equipment examination than the simple judgment of the doctors. Some examinations are really necessary since they can provide more accurate information, but this often becomes some doctors' excuse (in fact they know the information with high accuracy can avoid medical dispute). This kind of doctors violates the professional ethic. They suggest the patients to have examinations when they could identify the disease through clinical examination. They suggest various examinations when one of them is enough. For example, they use B-mode instead of X machine; they suggest color Doppler ultrasound instead of black and white B-mode. In some cases, it is not necessary to have some examinations, such as CT and MRI is not necessary for the thyroid nodule disease. Yu Dezhi, the deputy director of the Ministry of Health, pointed out, "The examination fees is the fastest-growing item in the medical expenditure during the past two years. It has increased at more than $20 \%$ every year, and more than 100 billion yuan was invested in sophisticated equipment." These equipments have been widely used. However, the research of Lei Haichao confirms that $16.3 \%$ of the CT examination was unnecessary. The examination with lower price can work well to these patients. According to the statistics, the proportion of the CT's positive result is $10 \%$ in China, while the world average is $50 \%$. The market-clearing price is $p=P_{s}(z) \equiv F_{s}^{-1}(1-z)$, so $s \in S$ is a group of demand curves with different dispersed parameters.

\subsubsection{Introduce the information accuracy}

Assume the difference between the information from specialists and ordinary doctor is that the accuracy is not the same. Suppose the accuracy of the information per unit is $\beta \in[0,1]$, in which $\beta=0$ means the information that the patients get is completely wrong, and $\beta=1$ means it is absolutely correct. For the same unit information, the mean of the accuracy is higher than the one from ordinary doctors, that is $E\left(\beta_{E}\right)>E\left(\beta_{C}\right)$. One reasonable assumption is that $F_{s}(\theta)$ is a decreasing function, which means the function is the first-order stochastic dominance (Erich L.Lehmann, 1955). Specifically, $E \underset{F S D}{\geq} C \Leftrightarrow F_{s B}(\theta) \leq F_{s N B}(\theta)$ means $S$ would increase when personal brand contains the accuracy of the information, which will decrease the cumulative distribution function $F_{s}(\theta)$. The reason to make such assumption is that the main difference between the information from doctors with personal brand (specialists) and the one without is the accuracy of the information. Suppose the unit information with personal brand (information from specialists) is $E$ and the one without personal brand (information from ordinary doctors) is $C$. It turns out that the first-order stochastic dominance of $E$ by $C$, which means to the individuals whose Utility function is increasing in the accuracy and Continuous, they would prefer the information with high accuracy; or when $E$ and $C$ is the same( i.e. the higher the accuracy of the information, the better.), he patients would not prefer the information with low accuracy. The probability of E's mean above a certain level is higher than C's. Patients who are infinite for the accuracy $\beta$ would prefer information from specialists $E$. This is not only a sufficient condition, but also a necessary condition. Please note that for the condition that the patients are infinite for the accuracy, its necessary and sufficient condition is that their utility function of accuracy is strictly increasing. From the economic point of view, the demand curve moves outward as $s$ increasing. In other words, the distribution is more dispersed as $S$ increasing, resulting greater heterogeneity for the consumers. This also shows in the change of the density function $f_{s}(\theta)$ : the center of it moves downward and 
the "tails" at both sides moves upward. When the accuracy $\beta$ is higher, consumers' maximum willingness to pay for the unit information is higher, that is $\theta$ is bigger. Then the function about $\theta$ and $\beta$ is $\theta=g(\beta, \gamma)$, in which $\gamma$ is other factors affecting $\theta$, including income $m$,etc. We obtain

$\frac{\partial \theta}{\partial \beta}=\frac{\partial g(\beta, \gamma)}{\partial \beta}>0, \frac{\partial \theta}{\partial m}>0, \frac{\partial^{2} \theta}{\partial \beta^{2}}<0$,

which means the price that patients are willing to pay the unit information is increasing as the increase of its accuracy and the income of the consumers. The second derivative of $\beta$ is less than 0 means when the accuracy increases at a certain level, that is the accuracy of the information is getting increasingly closer to 1 for $\beta \in[0,1]$, the marginal price that the patients are willing to pay the accuracy of unit information is gradually decreasing. (Since the accuracy is assumed uniformly distributed in every unit of information, the accuracy per unit information obeys uniform distribution. The average accuracy per unit information of specialists, that is the mean of the accuracy, is larger than the ordinary doctors.) Summed up the changes of the density function, we draw the figurer below

\section{Figure 1}

The relationship between the price consumers are willing to pay and accuracy after personal brand is introduced in and the change of the density function

\subsection{Preference for the specialists or not}

2.2.1 The properties of the utility function

Suppose the utility function of the patients is $U(\theta, \beta)$ with the following properties, (1) $U(\theta, \beta)>0$, which means the utility of information that the patients get from doctors is positive;

(2) $\frac{\partial U(\theta, \beta)}{\partial \beta}>0$, which means for unit information patients always prefer the one with high accuracy when $\theta$ is fixed.

(3) $\frac{\partial U(\theta, \beta)}{\partial \theta}>0$, which means when $\beta$ is fixed, the utility of a patient is increasing as he pays more. If $\beta$ provided by specialists and ordinary doctors are the same, rational consumers will choose the one with lower price. However, as patients have time cost and preference for the "Psychological comfort", the ones who pay more for the same information get higher utility. If $U_{1}(\theta, \beta)<0$, the patients' utility is decreasing as $\theta$ increases when the accuracy is fixed. In other words, when the accuracy of the information offered by specialists and ordinary doctors is the same, the patients get lower utility paying Price premium to the specialists; but what is optimal for patients is utility maximization,, so there will nobody choose the specialists based on above analysis, which is at variance with reality.

\subsubsection{The three kinds of consumers}

To the three kinds of patients mentioned above, the distribution of them becomes more dispersed when they know the information is from specialists. The first kind of patients will give a higher price, that is $\theta$ increases, and their utility increase too. The second kind of patients is indifferent to the information either from specialists or ordinary doctors, so $\theta$ will not change, as well as patients' utility. The third kind of patients will give a lower price when knowing the information is from specialists because they do not prefer to it. According to the 
third property, when $\theta$ decreases, the utility of the third kind of patients decrease, too. In reality most patients belong to the first kind, but a few in the third.

For the first kind of consumers, $\theta_{E}>\theta_{C}, U\left(\theta_{E}, \beta\right)>U\left(\theta_{C}, \beta\right)$.

For the second kind of consumers, $\theta_{E}=\theta_{C}, U\left(\theta_{E}, \beta\right)=U\left(\theta_{C}, \beta\right)$.

For the third kind of consumers, $\theta_{E}<\theta_{C}, U\left(\theta_{E}, \beta\right)<U\left(\theta_{C}, \beta\right)$.

As most patients belong to the first group, they believe that the probability of the information's accuracy above a certain level is higher when there is personal brand of the doctors in the unit information, which resulting the increase of the mean of $\theta$ 's distribution $\mu(s)$. This article focuses on the first group of consumers in the rest of the paper. Actually, if only analyze the first kind, the mean of $\theta$ also becomes dispersed as the personal brand introduced in the information. In spite of all patients prefer to the information from specialists, how much they prefer is not the same. They may give quiet different price premium for the same information, which lead the dispersed parameter $S_{B}>S_{N B}$. It is because the increase of the mean, the fee paying to the specialists is higher than others in general hospital.

The third property also explains why many rich people hire private doctors. The payment for the private doctors is higher than other doctors, so the patients' utility must increase as they pay more. Otherwise, they pay more, but their utility decrease. The utility of these people not only contains $\theta$ and $\beta$, but also some other factors; so for the same information, the utility getting from specialists is higher than from ordinary doctors for these patients (such as additional utility from the reorganization of their social status). Fig.1 shows when the accuracy $\beta$ increases for one unit, the price that the first group is willing to pay for the specialists increases fast, but slowly for the ordinary doctors. This is the reason why doctors give different price levels of examinations and medicines to the patients according to their "background" (public medical care or at their own expense, income, etc.). This is obviously a problem of asymmetric information: the doctors have more information compared to the patients, for example, doctors knows the two kinds of medicine are similar in their ingredients but quite different in price, so the patient lacking of knowledge believe the personal brand of the doctors and the product brand of the hospital. In this situation, the demand curve of the information is lack of elasticity. From the analysis below we can see the demand curve rotates in a clockwise direction when the dispersed parameter increases. Then the demand curve becomes lack of elasticity, which lead the patients have lower price sensitivity. At the same time, the price rises fast as the increase of the accuracy. That is why the hospital could implement price discrimination.

\subsection{The variation of demand curve}

The dispersed density function causes the clockwise rotation of the distribution function. $0 \leq F_{s}(\theta) \leq 1$ is equal to the area enclosed by the horizontal axis and the density curve. The figure of density function, Fig.1, shows that the unit information with personal brand is more dispersed (the two "tails" cover more area), which causes the cumulative distribution function is large at the beginning. After the first intersection of the two density function, the area enclosed by the dotted line becomes larger than the area enclosed by the solid line. When the value of the density function increase to a certain point $\theta_{s}^{+}$, the two shaded areas is equal and the distribution function is the same. As the total area is 1 and the area enclosed by dotted lines are more concentrated, the rate of its increase is higher than the area enclosed by solid line after $\theta_{s}^{+}$. After the second intersection of the two density functions, the distribution function represented by solid line begins to grow faster than the dotted line. Since the total area is fixed, the two distribution functions, which will converge to 1, will not intersect again. This means the two distribution parameter have single rotating point $S$. When $S$ is continuous, there exists some rotating point $\theta_{s}^{+}$, so that if $\theta<\theta_{s}^{+}$, then $F_{s}(\theta)$ is an increasing function for $s$; 
if $\theta>\theta_{s}^{+}$, then $F_{s}(\theta)$ is a decreasing function for $s$. Fig.2 shows cleasly, in which the vertical axis represents the cumulative distribution function $F_{s}(\theta)$ and the horizontal axis represents $\theta$.

Figure2

The clockwise rotation of the distribution function after personal brand is introduced in

\subsubsection{The coordinates of the rotating points}

In this figure, if $\theta=\theta_{s}^{+}$, then $F_{s N B}(\theta)=F_{s B}(\theta)$; if $\theta<\theta_{s}^{+}$, then $F_{s B}(\theta)>F_{s N B}(\theta)$; if $\theta>\theta_{s}^{+}$, then $F_{s B}(\theta)<F_{s N B}(\theta)$ because of $\int_{-\infty}^{+\infty} f_{s}(\theta) d \theta=1$. As $z_{s}^{+}=1-F_{s}\left(\theta_{s}^{+}\right),\left\{P_{s}(z)\right\}$ is also represents a rotation sequence of the demand curve. The increase of $s$ causes the demand curve rotates around $(z, p)=\left(z_{s}^{+}, \theta_{s}^{+}\right)$. (Note 1)How to find the equation of the rotating points? According to the distribution function's qualities, we have $F_{s}(\theta)=F\left(\frac{\theta-\mu(s)}{\sigma(s)}\right) \cdot F(\cdot)$ in the function is a continuous distribution function whose mean is 0 , Variance is 1 and density function is strictly positive. $\mu(s), \sigma(s)$ are continuously differentiable functions, and $\sigma(s)$ satisfies the condition: $\sigma(s)>0, \sigma^{\prime}(s)>0$. The demand curve satisfies $P_{s}(z)=\mu(s)+\sigma(s) P(z)$, in which $P(z)=F^{-1}(1-z)$. The increase of $s$ causes the increase of $\sigma(s)$, and the change of $s$ affect the mean; so the overall effect include rotation and the movement of the mean (i.e. the movement of the demand curve). The net effect is the clockwise rotation of the demand curve. Here "rotation" is the rotation in a broad sense (Johnson and Myatt, 2006). In fact we suppose $\sigma(s)=s$ without loss of generality, then the demand curve change into $P_{s}(z)=\mu(s)+s P(z)$. In order to find coordinates of the rotating point, here suppose when dispersed parameter $s$ has small changes in the value, that is $s_{B}-s_{N B} \rightarrow 0$, the rotating point satisfies $P_{s B}(z)=P_{s N B}(z)$ since $z=1-F_{s}\left(P_{s}(z)\right)$, that is $P_{s N B}(z)=\mu\left(s_{N B}\right)+s_{N B} P(z)=\mu\left(s_{B}\right)+s_{B} P(z)=P_{s B}(z) \quad$. Rearranging this equation we have $P(z)=\frac{\mu\left(s_{N B}\right)-\mu\left(s_{B}\right)}{s_{B}-s_{N B}}=\lim _{s_{B} \rightarrow s_{N B}}\left[\frac{\mu\left(s_{B}\right)-\mu\left(s_{N B}\right)}{s_{B}-s_{N B}}\right]=-\mu^{\prime}(s)$.This indicates that the coordinates of the rotating point satisfies $z_{s}^{+}=1-F\left(-\mu^{\prime}(s)\right)$, in which only when $\mu^{\prime \prime}(s) \geq 0, z_{s}^{+}$is an increasing function. And when $P(z)=-\mu^{\prime}(s)$, we have $P_{s}(z)=\mu(s)+s P(z)=\mu(s)-s \mu^{\prime}(s)$, that is $\theta_{s}^{+}=\mu(s)-s \mu^{\prime}(s)$. (Note 2) Thus the location of the rotating point also depends on the changes of $s$. The rotation of the demand curve is shown in the following figure.

Figure 3

The clockwise rotation of the demand curve after personal brand is introduced in 2.3.2 Monopoly price in hospital

From the analysis above we can draw following conclusions: since the personal brand is introduced in, the consumers' demand curve for the information rotates in a clockwise direction, causing the elasticity of the curve became smaller; Even if the accuracy $\beta$ is the same, consumers are willing to pay more for the information 
from specialists, which is useful for the hospital to implement the second-degree price discrimination. The products of the hospital, which is a special information enterprise, contain information and common products (such as prescription drug). To the hospital, the income from information accounts for a large portion. The key features of information product are the marginal cost is very low and most of fixed cost is sunk cost, such as the fee for the medical devices. The marginal cost for the doctors to handle one more case is very low, which means the marginal cost for unit information is low. Therefore, if the hospitals determine the price according to the principle $M R=M C=P$, their cost for manpower and devices cannot be compensated. In this case, hospitals do not have motivation to produce much information at the optimal pricing determined in the perfectly competitive markets. In reality, implementing monopoly pricing, the hospitals determine a price higher than the equilibrium price to compensate the fixed cost and get high profit. These "information" is scarce in reality, especially the information from the specialists, and the consumers are heterogeneous; so when the price that the consumers are willing to pay for the unit information is more dispersed, the hospital have motivations to classified the information into different kinds, general, associate professor and professor. The hospitals implement price discrimination by the information with different prices that consumers choose. As the personal brand, product brand and enterprise brand are an indivisible whole, what is the relationship among them? This article will try to put them in a framework to analyze in the following part of this paper.

\section{The relationship among personal brand, product brand and enterprise brand}

Above analysis has shown the importance of the personal brand for the enterprise. At the same time, the product brand also plays an important role in promoting the enterprise brand. On the contrary, a "famous" enterprise can bring popularity to the individuals and products. $r, c$ and $q$ indicate the value of the personal popularity, product popularity and enterprise popularity. At the same time the three variables satisfy $r, c, q \in[-1,1]$ : if the popularity is 0 , nobody knows it; if the popularity is 1 or -1 , all consumers know it. When the three parameters are positive, high popularity means the success of brand building; conversely, it means the higher the popularity's absolutely value, the more harmful for the brand building. Take Sanlu Group as an example: when the negative popularity of the product increased, the enterprise popularity increased negatively. $R, C, Q$ indicate three continuous random variables. In order to facilitate the analysis, this article only takes the positive value of the three parameters to analyze. In other words, when popularity increasing, the brand building is more successful. In reality the three parameters can take the value 0 and the endpoint value 1 , so the interval is $[0,1]$.

\subsection{The correlativity among the popularities}

Here suppose $q$ is a function only with $r$ and $c$. In the early days of the enterprise, personal popularity $r$ and product popularity $c$ should go ahead of the enterprise popularity $q$. Otherwise, the enterprise, which only has enterprise popularity but no personal popularity and product popularity, cannot exist. That means every enterprise which enjoying high popularity are support by personal popularity and product popularity. At the later stage of the enterprise, the increase of $q$ causes the increase of $r$ and $c$. The enterprise enjoying high popularity could enhance the popularity of the subsequent products, as well as the individuals employed later. $r$ and $c$ are not independent, because high personal popularity could enhance the product popularity during a long time (e.g. some common products are represented by some famous people); conversely, high product popularity could enhance the personal popularity (e.g. the popularity of a common people may increase since he represents a well-known product). Suppose $q$ is a function of $r$ and $c$, i.e. $Q=h(R, C)$. As $r$ and $c$ are not independent, we have $k(r, c) \neq k_{R}(r) \cdot k_{C}(c)$, where $k(r, c)$ is the joint density function of the two-dimensional random variables $(R, C)$. Then we have:

$$
\begin{gathered}
k_{R}(r)=\int_{0}^{1} k(r, c) d c, \\
k_{C}(c)=\int_{0}^{1} k(r, c) d r .
\end{gathered}
$$

Function (1) and (2) are called the marginal density function about $R$ and $C$ of the two-dimensional random variables $(R, C)$. Since $r$ and $c$ are on the interval $[0,1]$, the distribution function of the enterprise's popularity $q$ is 


$$
F_{Q}(q)=P\{Q \leq q\}=P\{h(R, C) \leq q\}=\iint_{h(r, c) \leq q} k(r, c) d r d c
$$

which implies the density function of $q . q$ is a increasing function to $r$ and $c$, and the interval of the three parameters is $(0,1)$. Since the upper limit of the enterprise popularity is 1 , the rate of the increase become slower. In the early days of the hospital, the enterprise popularity increases significantly when well-known specialists are hired. As the popularity of the hospital reaches at a certain level, the effect will not work as well as before. The product brand is similar to the personal brand: as the increase of the product popularity, the enterprise popularity is increasing. After it reaches at a certain level, this effect will decrease. Therefore, we have the following formula:

$$
\frac{\partial q}{\partial r}>0, \frac{\partial^{2} q}{\partial r^{2}}<0 ; \frac{\partial q}{\partial c}>0, \frac{\partial^{2} q}{\partial c^{2}}<0
$$

which indicates that enterprise popularity is directly proportional to personal popularity. Except increasing positively, personal popularity mentioned here may increase by some negative news, which can also enhance the enterprise popularity. For example, Vanke once had a crisis of confidence because the chairman, Wangshi, had said some improper words for the donation of company to the disaster area of Wenchuan County. This caused the popularity of Vanke increased negatively. The popularity of the enterprise could increase positively or negatively, but the negative increase is unfavorable for the brand building. Similarly, high product popularity could increase the enterprise popularity. For example, since KFC is well known in China, the popularity of "Yum" will increase too. However, the negative increase of the product popularity could cause the negative increase of the enterprise popularity, which is unfavorable for the brand building too. For example, the inferior products make the popularity of Sanlu increase, but that is a fatal blow for the brand.

\subsubsection{The long-term and short-term correlativity between the product popularity and personal popularity}

In a short time $\operatorname{cov}(R, C) \leq 0$, while $\operatorname{cov}(R, C)>0$ in a long time. In the premise that the resource of the enterprise is scarce, the enterprise only uses the resources to build the product brand and personal brand. The former one includes the building of the sales channel and investing for research and development, etc. And the latter one includes investment in human resources development, etc. Suppose in a short time if the enterprise focus on the personal brand building (e.g. inviting famous people to represent the new product or inviting well-known specialists into the newly-built hospital), then the investment for product brand building will decrease. The "income effect" of personal brand building is the popularity of the enterprise increased, while the "substitution effect" is less investment of product brand building (e.g. the sales channel may diminish as the limitation of capital, which will cause the decrease of the product brand). In this case the substitution effect is stronger than the income effect. In the long run, since there is time effect, the diffusion of personal popularity will cause the enterprise popularity increase to a larger value, which will finally enhance the product brand for the positive correlation between the enterprise brand and product brand. In this case the income effect is stronger than the substitution effect, which means product brand and personal brand have a positive correlation.

\subsubsection{An example for a value}

Here take a special case as an example: suppose $q=\frac{1}{2} \sqrt{r}+\frac{1}{2} \sqrt{c}$ which satisfies the formula (4). If $r \rightarrow 1$ and $c \rightarrow 1$, then $q$ tends to 1 ; if both the two parameters tend to 0 , then $q$ tends to 0 . Therefore, the

formula (3) changes into: if $q \leq 0$, the density function of $Q$ is $F_{Q}(q)=0$; if $q \geq 1$, then $F_{Q}(q)=1$; if

$$
0<q<1 \text {, then } F_{Q}(q)=\iint_{h(r, c) \leq q} k(r, c) d r d c=\int \underset{\frac{1}{2} \sqrt{r}+\frac{1}{2} \sqrt{c} \leq q}{\iint} k(r, c) d r d c, \text { where } \mathrm{q}=1 / 2 \text { is the critical point. }
$$

The upper limit of $c$ is 1 . Since the value of the distribution function is equal to the area enclosed by the density function and the two axes, we have to use the piecewise calculation to find the distribution function.

Figure 4

Piecewise calculating graph of distribution function for the enterprise popularity Q 


$$
\begin{aligned}
& \text { If } 0<q \leq 1 / 2 \text {, we have } F_{Q}(q)=\underset{\frac{1}{2} \sqrt{r}+\frac{1}{2} \sqrt{c} \leq q}{\iint} k(r, c) d r d c=\int_{0}^{4 q^{2}} d r \int_{0}^{(2 q-\sqrt{r})^{2}} k(r, c) d c \\
& \text { If } 1 / 2<q<1 \text {, we have } F_{Q}(q)=(2 q-1)^{2}+\int_{2 q-1)^{2}}^{1} d r \int_{0}^{(2 q-\sqrt{r})^{2}} k(r, c) d c
\end{aligned}
$$

Given the joint density function $(R, C)$ is $k(r, c)$, we could find the distribution function by drawing the graph. Then the density function could be found, too. The equation $q=\frac{1}{2} \sqrt{r}+\frac{1}{2} \sqrt{c}$, whose planar projections both in $(q, c)$ and $(q, r)$ are concave function, satisfies formula (4). The graphs are

\section{Figure 5}

The projection of the enterprise popularity function in the plan of (q,c) and (q,r)

Figure 6

The graph of the enterprise popularity function

3.1.3 The covariance matrix of the brand popularity

Here define the covariance matrix of the brand awareness as follow,

$$
\nabla=\left(\begin{array}{ccc}
D Q & \operatorname{Cov}(Q, R) & \operatorname{Cov}(Q, C) \\
\operatorname{Cov}(R, Q) & D R & \operatorname{Cov}(R, C) \\
\operatorname{Cov}(C, Q) & \operatorname{Cov}(C, R) & D C
\end{array}\right)
$$

in which all elements are greater than 0 in a long run, that is they have positive correlation. When all variances of $Q, R, C$ are not 0 , we define the correlation coefficient between enterprise popularity and personal popularity is $\rho_{Q R}=\frac{\operatorname{Cov}(Q, R)}{\sqrt{D Q} \cdot \sqrt{D R}}$, the correlation coefficient between enterprise popularity and product popularity is $\rho_{Q C}=\frac{\operatorname{Cov}(Q, C)}{\sqrt{D Q} \cdot \sqrt{D C}}$, and the correlation coefficient between product popularity and personal popularity is $\rho_{R C}=\frac{\operatorname{Cov}(R, C)}{\sqrt{D R} \cdot \sqrt{D C}}$, where $\operatorname{Cov}(R, C)=E[(R-E R)(C-E C)]$.

Assume the two-dimensional continuous random variable $(R, C)$ is a normal distribution with parameters $\mu_{1}, \mu_{2}, \sigma_{1}^{2}, \sigma_{2}^{2}, \rho_{R C}$, in which $\mu_{1}, \mu_{2}, \sigma_{1}^{2}, \sigma_{2}^{2}, \rho_{R C}$ are all constants and $\sigma_{1}>0, \sigma_{2}>0,0<\rho_{R C}<1$. (Here assuming the variables satisfy a normal distribution is reasonable, because generally the popularity of product, personal and enterprise are higher around the location of the enterprise, so the distribution is more concentrated; the popularity may rise or diminish as the geographic distance increases, so the distribution becomes more dispersed. This indicates that the probability is large when the popularity is in the value of mean, while it is small when the popularity is in the areas of normal distribution's "tails".) Then we get the joint density function:

$$
k(r, c)=\frac{1}{2 \pi \sigma_{1} \sigma_{2} \sqrt{1-\rho_{R C}^{2}}} \exp \left\{-\frac{1}{2\left(1-\rho_{R C}^{2}\right)}\left[\left(\frac{r-\mu_{1}}{\sigma_{1}}\right)^{2}-2 \rho \frac{r-\mu_{1}}{\sigma_{1}} \cdot \frac{c-\mu_{2}}{\sigma_{2}}+\left(\frac{c-\mu_{2}}{\sigma_{2}}\right)^{2}\right]\right\}
$$


which implies that the marginal distribution $R, C$ of the two-dimensional normal distribution $(R, C)$ is one-dimensional normal distribution $N\left(\mu_{i}, \sigma_{i}^{2}\right)$, where $i=1,2$. Thus the equations of (1) and (2) can be solved, and then get the distribution function and density function of the enterprise popularity. At last the equations of (5) and (6) can be solved too. Obtaining these density functions, we can get all elements in the covariance matrix of the brand awareness and then the correlation coefficients of the enterprise popularity, personal popularity and product popularity. According to the value of the correlation coefficient we can compare $\rho_{Q R}, \rho_{Q C}$, that is solve the problem that which has higher degree of correlation with enterprise

popularity. At the same time, $\rho_{R C}$, the correlation coefficient of the product popularity and the person popularity, can also be abstained.

\subsection{The indifferent enterprise popularity curve and the optimal position determination}

Suppose the enterprise is the "producer" of personal popularity and product popularity, and the enterprise faces with the "production possibility frontier" as it subject to resource constraints. Assume $Z_{c}$ is the amount of resource inputted into the product popularity, where $C=C\left(Z_{c}\right)$, that is the enterprise should input the amount of $Z_{c}$ to the product brand building to ensure the product popularity of a given number (as showed in the second quadrant); $Z_{r}$ is the amount of resource inputted into the personal popularity, where $R=R\left(Z_{r}\right)$, that is the enterprise should input the amount of $Z_{r}$ to the personal brand building to ensure the personal popularity of a given number (as showed in the forth quadrant). The first quadrant of the following figure is the enterprise's "Production possibility frontier" for personal popularity and product popularity:

Figure 7

The graph of the product popularity function, personal popularity function and indifferent enterprise popularity curve

In this figure, $q^{*}, q^{* *}$ are indifferent enterprise popularity curves. The implicit assumption here is the high enterprise popularity could be translated into revenue, and we will explain the transformation conditions later. $Z_{r}+Z_{c}=Z$ in the third quadrant is the resource constraint line, where $Z$ is the total amount of resource belongs to the enterprise. Assume the resources invested in personal popularity and product popularity is homogeneous, and the resource that the enterprise owned can be quantified, of which the unit price is 1 . The intersection of $Z$ curve with the vertical axis shows that the enterprises input all resources into the personal popularity building. For the hospital, that means all resources are used to hire well-known specialists. In this case the popularity of the hospital totally depends on the personal popularity. This is not optimal from the analysis below. In a long run, the spread of the personal popularity could cause the increase of the enterprise popularity. Under the assumption that the high enterprise popularity could be translated into revenue, as the enterprise popularity increases, the direct result is the revenue will rise. In such a case the "production possibility curve" will move outward, which means the enterprise will have more resources to build the product brand (input more resource in the product brand building, such as building the sales channel, can cause the increase of the product 
popularity). Suppose the personal brand and enterprise brand compose a "compound" brand. What the consumers have remembered are the famous specialists of a certain hospital or the famous products of a certain hospital. This means the high popularity of the products and individuals can also enhance the popularity of the enterprise, which the different between the two elements is that the degree of the correlation is not the same. From the tangents of resource constraint line, curve of the equal enterprise popularity and production possibility shown in the figure above, we could kwon how to allocate resource between personal popularity building and product popularity building, such as the point $\left(R^{*}, C^{*}\right)$.

\section{Conclusion and future research direction}

This article suppose $q$ is a function only with $r$ and $c$, i.e. $q=h(r, c)$. However, in reality other factors may also affect the enterprise popularity, so we have $q=h(r, c, \varepsilon)$, where $q$ is the second-order continuous differentiable function to $r$ and $c$, and parameter $\varepsilon$ indicates the effect of other factors for the enterprise brand (hospital brand), including the quality of service and the condition of the hospital's hygiene and transportation, etc. The personal popularity satisfies $r=h^{-1}\left(q, \varepsilon_{1}\right)$, and the product popularity satisfies $c=h^{-1}\left(q, \varepsilon_{2}\right)$. The error item $\varepsilon_{1}$ contains the rest of variables affecting the personal popularity, including his education background (master, doctor or a returning student), experience of internships, the previous work and practice experience (experiences of participating in projects), etc. The error item $\varepsilon_{2}$ contains the rest of variables affecting the product popularity. When the enterprise enjoins high popularity, the personal popularity will also increase, which is obvious in the chief economist system. A typical example is the former Morgan Stanley chief Asian economist Andy Xie. The high popularity of Morgan Stanley could increase the personal popularity of the chief economist, but for one brand the rate of increase will diminish as the enterprise popularity increase one more unit.

\subsection{Conclusion}

This article merely uses the personal popularity, product popularity and enterprise popularity to indicate the personal brand, product brand and enterprise brand. However, in reality the high product popularity and personal popularity do not mean that the enterprise could get the consumers' vote (i.e. currency). Thus the important question for the enterprise is how to translate the high enterprise popularity into revenue. In other words, how can make the consumers choose the products of this enterprise? Our answer is only the high brand credit degree (Sun and Liu, 2006) could ensure the choice of the consumers' without thinking. Brand credit degree means how much degree the enterprise has done to the category which it had promised to the target customer by exclusive symbol. Category here means the products' single profit point for the customer to choose. Only when the enterprise promised to be the representative of a certain category and perfectly done it can satisfy the customers' psychology of purchasing. Conversely, if the promise is ambiguous or meaningless, then the brand will lose its value to the consumers, so consumers will not choose this kind of high popularity brand. This is the very reason that lots of private hospitals focus on the single category of "Specialist Hospital". If the private hospital makes some ambiguous promise, although it gets the high popularity by advertisement, the consumers' choice cost will increase for the complex category. In addition, if the consumers transfer to this private hospital from previous hospital, their switch cost will increase too. As the consumer's optimal choice indicates the choice will bring them utility maximization and cost minimization, so the rational consumers will not choose this private hospital. Similarly, the law of single category also fits the public hospital. While many public hospitals contain a number of sections, they also highlight their "specialist or strength", which is their single category. Since many hospitals compete in the markets, the consumers face with a large alternative choice collection, which means the consumers' choice cost is great. However, the strategy of the single category reduces the consumers' choice cost 
to a large extend, so rational consumers will choose this kind of brand. Therefore, if the high popularity cannot reduce consumers' choice cost by increasing the brand credit degree, then the high popularity cannot work and it will gradually decrease to 0 with the passage of time. On the contrary, the high popularity will gradually increase to 1 with the passage of time.

\subsection{Future research direction}

The main traditional mode of transmission is advertisement which can only get the popularity but consumers' brand credit degree, because consumers absolutely know that advertisement is the enterprise' boast. Thus the biggest question for the enterprise is how to transfer the high popularity to the high credit degree. The analysis above shows only when the high popularity is obtained by reflecting the consumer's single profit point can this transfer be realized. This article only gives a rough framework on the correlation of personal brand, product brand and enterprise brand. To facilitate the mathematical treatment, this article uses the popularity to reflect the condition of brand building. Since the connotation of brand contains many factors, the future research direction is empirical analysis on popularity. This article supposes the popularity's absolute value is the ratio that the amount of people who knows this brand in every one hundred people. If the consumers have positive attitude towards this popularity, the increase of popularity means the brand building is successful; if their attitude is negative, the increase of popularity in the negative way is more harmful to the brand building. The personal brand building is the same. High personal popularity is not the symbol of the success of personal brand building. If the consumers have positive attitude towards this popularity, the personal brand building is failed. The mean and variance of the popularity could be obtained through questionnaire. Then according to the model of this paper we can get the density function and correlation coefficient of three kinds of popularity. Finally we can know the associated degree among the enterprise popularity, personal popularity and product popularity, which is helpful for the enterprise's brand building in the future. On February 23, 2010, the Ministry of Health, the five ministries and commissions jointly issued "on the reform of public hospitals, the pilot guidance", which allow the medical practitioners work more than one hospital. Before this reform, China's hospital market is segmented oligopolistic markets, namely public hospitals in the local market is an oligarchy. Considering the time cost and transportation cost, the total cost for consumers to choose the hospital with personal brand is much high. To allow medical practitioners to practice more than one places to some extent eased the geographical split. At the same time, this is helpful for the Chinese private hospitals to build the personal brand.

\section{References}

Aaker, D.A. (1996). Building strong brands. New York: The Free Press.

Aaker, J. L. (1997). Dimensions of brand personality. Journal of Marketing Research, 34, 347-356.

Bond, R.S., and Lean, D.F. (1979). Consumer Preference, Advertising and Sales: On the Advantage from Early Entry, Working Paper 14,Bureau of Economics, U.S. Federal Trade Commission, Washington.

Creyer, E. E Ross, W. (1996). The impact of corporate behavior on perceived product value. Marketing Letters, 7, 173-185.

De Chernatony, Leslie, Drury, Susan and Segal-Horn, Susan. (2003). Building a services brand: stages, people and orientations. Service Industries Journal, 3, 1-21.

Francois, Thisse. (1992). Sequential Entry with Brand Loyalty Caused by Comsumer Lerrning by-Using. The Journal of Industrial Economics, 40, 397-416.

Gabszewicz, Jean, Lynn Pepall, and Jacques-Lancaster, K.J. (1966). A New Approach to Demand Theory. Journal of Political Economy,74, 130-152.

Goldberg, Marvin E., and Hartwick, J. (1990). The Effects of Advertiser Reputation and Extremity of Advertising Claim on Advertising Effectiveness. Journal of Consumer Research, 17, 172-179.

Justin P. Johnson and David P.Myatt. (2006). On the Simple Economics of Advertising, Marketing, and Product Design. The American Economic Review, 96, 757-765.

Kapferer, J. N. (1997). Strategic brand management: Creating and sustaining brand equity long term. (2nd ed.). London: Kogan Page Limited.

Keller, K. L. (1993). Conceptualising, measuring and managing customer-based brand equity. Journal of Marketing, 57, 1-22.

Kelmperer, Paul. (1995). Competition When Consumers Have Switching Cost: An Overview with Applications to Industrial Organization. Macroeconomics, and International Trade, Review of Economic Studies, 62,515-540. 
Moorthy K S. (1984). Market Segmentation, Self-selection,and product line design. Marketing Science 3,4,289-307.

Mussa M, Rosen S. (1978). Monopoly and product quality. Journal of Economic Theory, 8, 2,303-317.

O'Cass, Aron and Grace, Debra. (2003). An exploratory perspective of service brand associations. Journal of Services Marketing, 5, $452-475$.

Runyon K.E. (1977). Consumer Behavior and the Practice of Marketing. Columbus: C.E.Merill.

Schlesinger, Harris, and J.-Mathias Graf von der Schulenburg. (1991). Search Costs, Switching Costs and Product Heterogeneity in an Insurance Market. Journal of Risk and Insurance, 55, 109-111.

\section{Notes}

Note 1. In the literature of Johnson and Myatt (2006), they suppose $s$ is a continuous variable to get the demand function from the cumulative distribution function. Here we consider that the localized change of $s$ is merely the change of the dispersed parameter before and after the personal brand introduced in, which will cause

the rotation of the distribution function $F_{s}(\theta)$. For $\theta \in\left(\theta_{s}, \bar{\theta}_{s}\right)$, it has $\theta>\theta_{s}^{+} \Leftrightarrow \frac{\partial F_{s}(\theta)}{\partial s}<0 . \theta<\theta_{s}^{+} \Leftrightarrow \frac{\partial F_{s}(\theta)}{\partial s}>0$. If all $s$ satisfy this formula, then $\left\{F_{s}(\theta)\right\}$ indicates a rotation sequence. It can be written as $z>z_{s}^{+} \Leftrightarrow \frac{\partial P_{s}(z)}{\partial s}<0 . z<z_{s}^{+} \Leftrightarrow \frac{\partial P_{s}(z)}{\partial s}>0$. To sold $z$ unit at price of $P_{s}(z)$, it must satisfy $z=1-F_{s}\left(P_{s}(z)\right)$. Thus we have

$$
F_{s}\left(P_{s}(z)\right)=1-z \Leftrightarrow F\left(\left(P_{s}(z)-\mu(s)\right) / \sigma(s)\right)=1-z \Leftrightarrow P_{s}(z)=\mu(s)+\sigma(s) F^{-1}(1-z)=\mu(s)+\sigma(s) P(z) .
$$

Note 2. Please turn to Johnson and Myatt (2006) to get the way solving coordinates of the rotating points. The analysis (James H. Myers and Allan D.Shocker, 1981) indicates that consumers' loyalty for a brand means they will transfer less to other brand if the price increases and they will more products of this brand if the price decrease. It will shape the demand curve as the letter "S", which is shown in Fig.3.

Table 1. The Proportion Of Information Products In The Per Capital Consumption In The Public Hospital In 2008

\begin{tabular}{|l|l|l|l|l|l|l|}
\hline Provinces & $\begin{array}{l}\text { Per capital } \\
\text { medical } \\
\text { expenditure } \\
\text { of } \\
\text { outpatients } \\
\text { (yuan) }\end{array}$ & $\begin{array}{l}\text { Drugs } \\
\text { fees } \\
\text { (yuan) }\end{array}$ & $\begin{array}{l}\text { Examination } \\
\text { and } \\
\text { treatment } \\
\text { fees (yuan) }\end{array}$ & $\begin{array}{l}\text { Per capital } \\
\text { medical } \\
\text { expenditure } \\
\text { of } \\
\text { inpatients } \\
\text { (yuan) }\end{array}$ & $\begin{array}{l}\text { Drugs } \\
\text { fees } \\
\text { (yuan) }\end{array}$ & $\begin{array}{l}\text { Examination } \\
\text { and } \\
\text { treatment } \\
\text { fees (yuan) }\end{array}$ \\
\hline Shandong & 154.4 & 77.0 & 52.1 & 4993.8 & 2360.4 & 1824.3 \\
\hline Jiangxi & 117.4 & 58.8 & 40.6 & 3955.1 & 1832.9 & 1432.3 \\
\hline Shanxi & 124.4 & 56.9 & 47.0 & 4382.3 & 1885.9 & 1458.5 \\
\hline
\end{tabular}

Notes: Shandong represents the east part; Jiangxi represents the middle part; Shanxi represents the west part. We take the examination and treatment fees as the information products consumption. The reason for not choose Beijing or Shanghai as the representation of the east part is the two cities have gathered a large number of well-known hospitals and lots of consumers come from other provinces.

The resource of the data: 2009 China Health Statistics Yearbook

Table 2. The Proportion of Information Consumption For The Outpatients And The Inpatients In The Time Axis 


$$
\begin{array}{|l|lll|ll|ll|l}
\begin{array}{l}
\text { Public } \\
\text { hospital }
\end{array} & 90 & 95 & 00 & 04 & 05 & 06 & 07 & 08 \\
\mathrm{~m} \% & 19.3 & 22.8 & 19.6 & 29.8 & 29.8 & 31.0 & 31.1 & 30.9 \\
\mathrm{Z} \% & 25.7 & 30.4 & 31.7 & 36.6 & 36.0 & 36.2 & 34.9 & 34.5
\end{array} \mid
$$

Note: $\mathrm{m}$ indicates the proportion of examination and treatment fees for the outpatients; $\mathrm{z}$ indicates the proportion of examination and treatment fees for the inpatients.

The resource of the data: 2009 China Health Statistics Yearbook
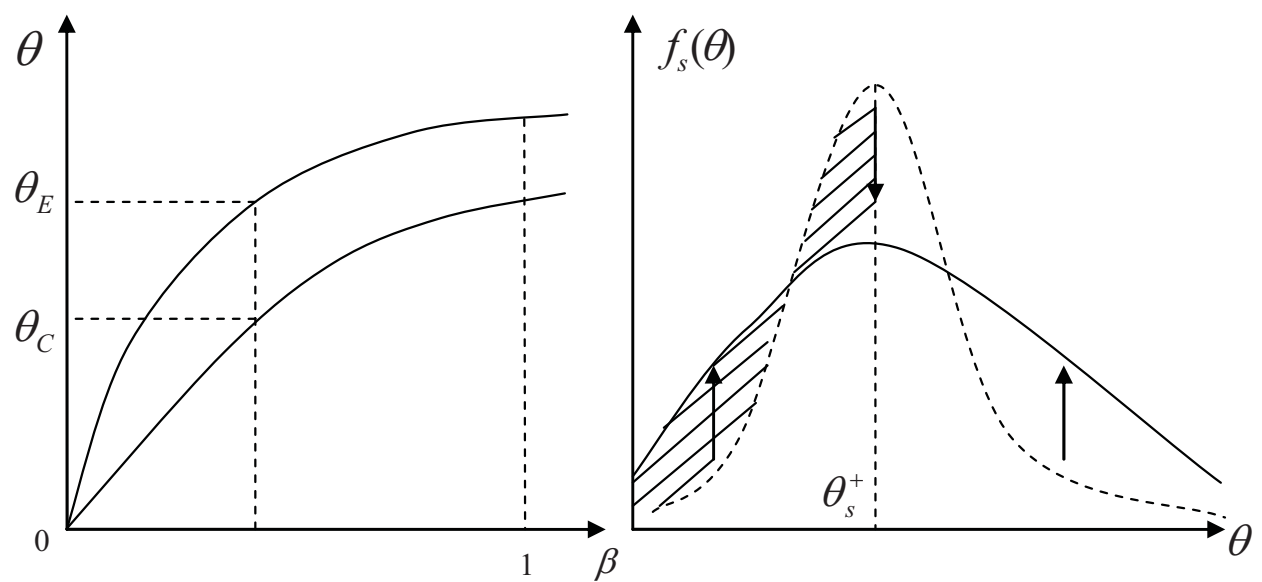

Figure 1. The Relationship between the Price Consumers Are Willing to Pay and Accuracy after Personal Brand Is Introduced in and the Change of the Density Function

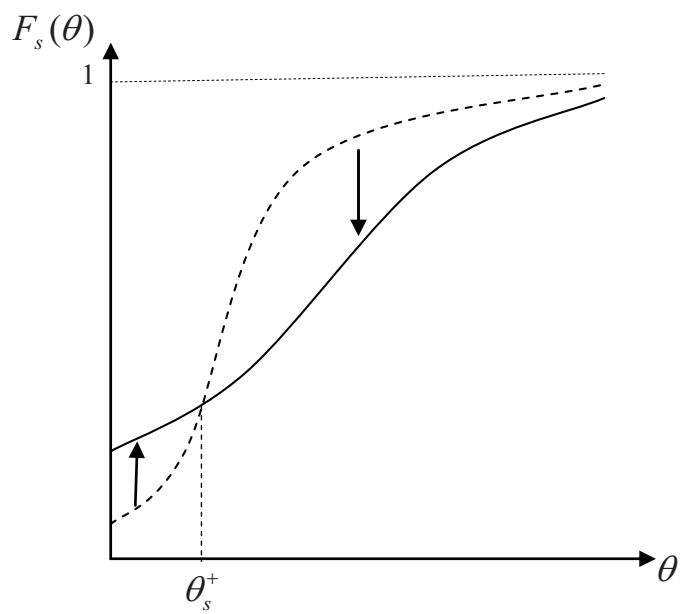

Figure 2. The Clockwise Rotation of the Distribution Function after Personal Brand Is Introduced In 


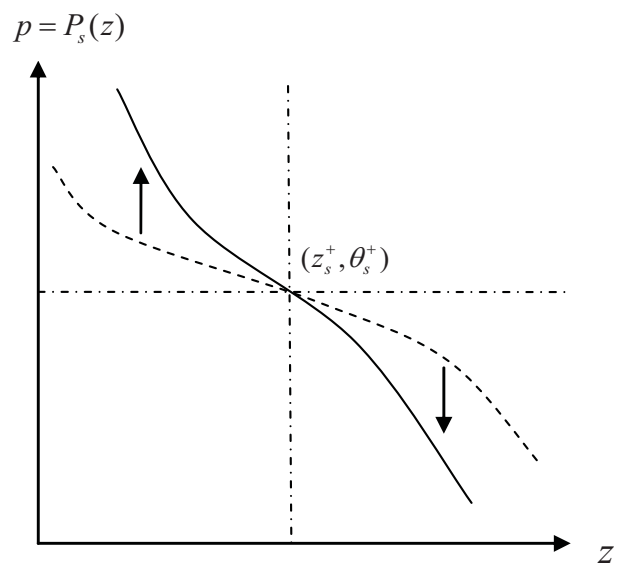

Figure 3. The Clockwise Rotation of the Demand Curve after Personal Brand Is Introduced In

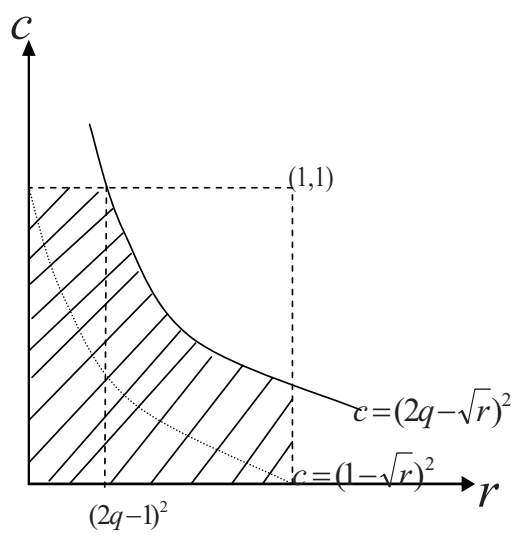

Figure 4. Piecewise Calculating Graph of Distribution Function for the Enterprise Popularity Q
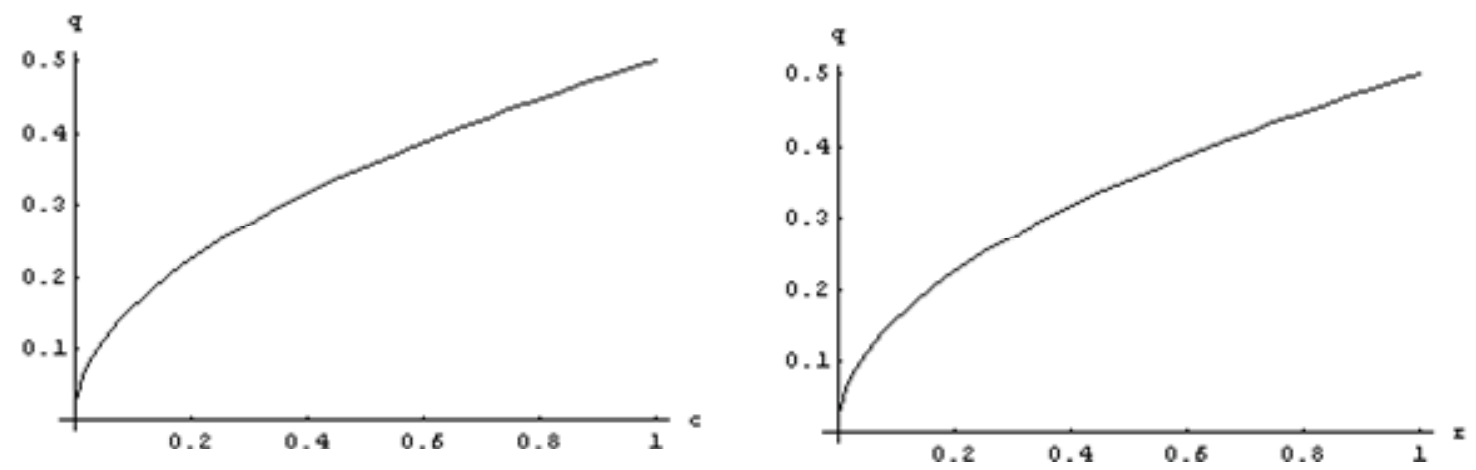

Figure 5. The Projection of The Enterprise Popularity Function in the Plan of (Q,C) And (Q,R) 


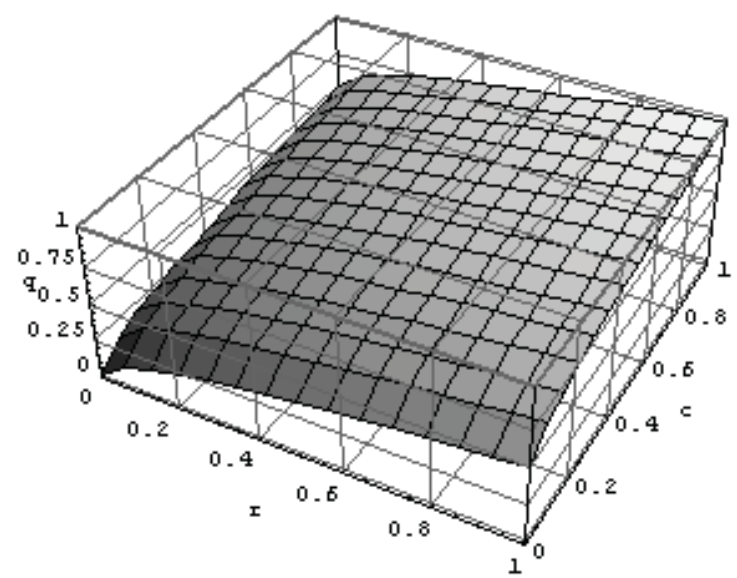

Figure 6. The Graph of the Enterprise Popularity Function

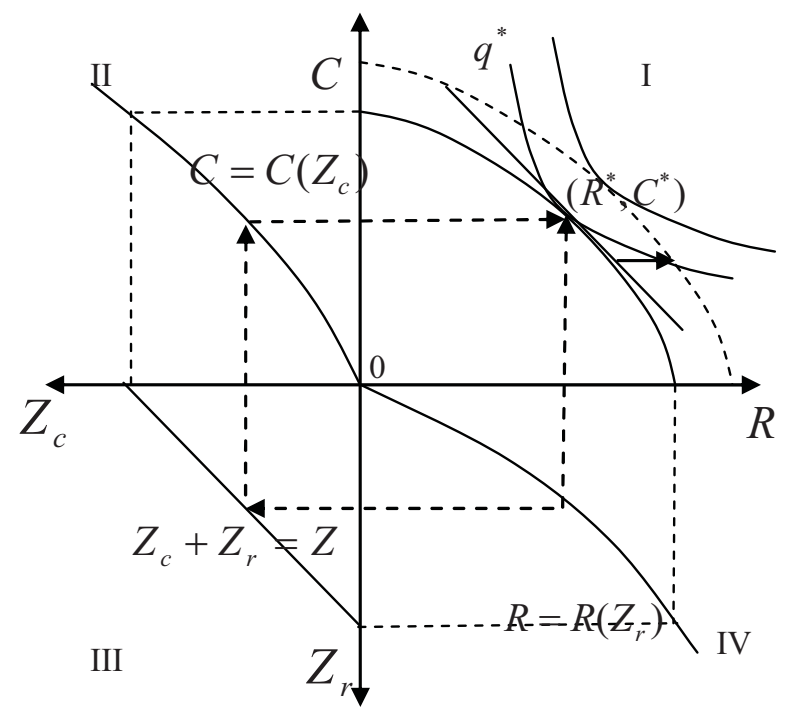

Figure 7. The Graph of the Product Popularity Function, Personal Popularity Function and Indifferent Enterprise Popularity Curve 